\title{
Using Social Cognitive Career Theory to Understand Why Students Choose to Study Computer Science
}

\author{
Amnah Alshahrani ${ }^{* \dagger}$, Isla Ross*, Murray I Wood* \\ *Department of Computer and Information Sciences, University of Strathclyde, Glasgow, UK \\ $\dagger$ Princess Nourah bint Abdulrahman University, Saudi Arabia \\ \{amnah.alshahrani | isla.ross | murray.wood\}@strath.ac.uk
}

\begin{abstract}
The aim of this research is to use Social Cognitive Career Theory (SCCT) to identify and understand reasons why students choose to study Computer Science (CS) at university. SCCT focuses on students' prior experience, social support, self-efficacy and outcome expectation. The research is partly motivated by the desire to increase female participation rates in CS, particularly in the UK. Policymakers can use the factors that both females and males identify as influencing their choice of studying CS to enhance the experiences of all students prior to coming to university, but female students in particular. The study uses a semi-structured interview with 17 mixed gender subjects currently studying CS at three Scottish universities. The findings are that social support from family, teachers, friends and mentors is a particularly important factor in choosing to study CS, especially for female subjects. The career paths offered by a CS degree is another major factor, not just the potential jobs, but also the general value of a CS education and the potential to make useful contributions to society. School education appeared to have limited influence, though exposure to problem solving, programming, online self-learning and internships are positive influences. The stereotypical view of CS students as 'geeks' is outdated and unhelpful - it is more appropriate to see them as 'analytical' or 'over-achievers'. Subjects make many suggestions for improving the CS education provided at school, especially to make it more attractive to females, including: make it compulsory, teach it earlier, include more programming and problem solving, and increase the visibility of female exemplars and role models.
\end{abstract}

\section{CCS CONCEPTS}

- Social and professional topics $\rightarrow$ Computer science education

\section{KEYWORDS}

Social Cognitive Career Theory; Gender; Computer Science; Education; Careers; Students.

\footnotetext{
Permission to make digital or hard copies of all or part of this work for personal or classroom use is granted without fee provided that copies are not made or distributed for profit or commercial advantage and that copies bear this notice and the full citation on the first page. Copyrights for components of this work owned by others than ACM must be honored. Abstracting with credit is permitted. To copy otherwise, or republish, to post on servers or to redistribute to lists, requires prior specific permission and/or a fee. Request permissions from Permissions@acm.org.

ICER '18, August 13-15, 2018, Espoo, Finland (C) 2018 Association for Computing Machinery. ACM ISBN 978-1-4503-5628-2/18/08 ..\$15.00 https://doi.org/10.1145/3230977.3230994
}

ACM Reference Format:

A. Alshahrani, I. Ross, and M. Wood. 2018. Using Social Cognitive Career Theory to Understand Why Students Choose to Study Computer Science. In Proceedings of ACM ICER conference, Espoo, Finland, August 2018 (ICER '18), 10 pages. https://doi.org/10.1145/3230977.3230994

\section{INTRODUCTION}

The gender gap amongst students choosing to study certain subjects at university has received considerable attention in recent years. In Western countries, Computer Science (CS) in particular has a gap that challenges governments, industry and education. For example, Pappas et al. [45] highlight the potential shortage in Europe: "The European Commission predicted that by 2020, in Europe, there will be a shortage of more than 800,000 professionals in the field of Computer Science". As a result of this huge increase in demand in technology fields, female representation in CS is now a key factor for the economic and labour market [7]. However, in countries such as Scotland, females make up only $16 \%$ of students studying CS at university [27]. Recently, there have been significant efforts from scholars and researchers to investigate this issue, to understand the factors that cause it, and to determine how it might be addressed.

This study contributes to that effort by using Social Cognitive Career Theory (SCCT) [37] to try to identify and understand the reasons that influence students to choose to study CS at university, particularly female students. Through understanding those reasons, it may be possible to change pre-university experiences to increase the likelihood of females choosing to study CS. The contribution of this study is to help policymakers design guidance to tackle the gender gap in CS.

SCCT is a framework for understanding how personal, cognitive and contextual factors influence career and/or academic choices. Its academic / career choice model consists of four components - prior experience, social support, self-efficacy and outcome expectation. This study used SCCT as a theoretical foundation from which to construct a semi-structured interview. Seventeen subjects (11 female, 5 male, 1 gender-neutral) participated, all of whom are currently studying CS at one of three Scottish universities. A qualitative, content analysis of the individual interview transcripts was then performed using NVivo [1].

The findings include the importance of social support from family, teachers, friends and mentors when choosing to study CS, particularly for females. Career paths offered by a CS degree is another factor - not just the range of jobs available, but also the general value of a CS education and the potential to contribute to society. The stereotypical views of CS students as 'geeks' are still prevalent but are seen as outdated by students themselves. The impact of current (pre-university) school education appears to be of 
limited significance but exposure to problem solving, programming, online self-learning and internships are important positive influences.

These findings have the potential to help schools, universities and other policymakers shape pre-university CS experiences into something more appealing. The results can be used to help present a more positive view of a CS education to schoolchildren, their families and their teachers. The results also contain numerous suggestions from subjects as to how this might be done, especially to make CS more attractive to females: make it compulsory, teach it earlier, incorporate more programming and problem solving, and increase the visibility of female exemplars and role models.

The next section includes a brief summary of previous research exploring factors that influence the choice to study CS. There is also a review of previous work that has used SCCT to understand academic choices. Section 3 presents a description of the qualitative study design. Section 4 is a brief description of the data analysis procedure. Section 5 presents a detailed description of the interview results. Section 6 presents the findings based on the results and relates them to prior research. The paper concludes with discussion of threats to validity in Section 7 and a summary of the findings, their implications and potential further work in Section 8.

\section{RELATED WORK}

\subsection{Factors Influencing the Choice to Study Computer Science}

A number of studies have discussed the factors that appear to make female students reluctant to study CS at university [7, 9, 35]. Moreover, scholars and researchers have explored why females are under-represented in Computer Science [35, 62]. Others have investigated the factors that influence students' intention to pursue a CS major $[12,17,36]$.

Some of the studies exploring the factors behind female underrepresentation in CS found that cultural factors influence choices made by students. Varma [60] investigated the factors behind the under-representation of females in CS and computer engineering at some higher education institutions in USA. In her study, "gendered socialization" (more support for boys) and "technology anxiety" were identified as key factors. In the UK, Sinclair and Kalvala [55] found that gender stereotypes (computer science for boys) and cultural expectations (parents' discouragement) were the significant factors that could influence the decisions of females not to study CS. Cohoon and Aspray [15] also argued that social and cultural factors affect gender participation in computing fields, not biological gender differences. In the Netherlands, Rommes et al. [49] found that teenagers seemed to be influenced by 'prototype' impressions of professions where the image of CS was male, 'nerdy' and unattractive. Wong [64] found that even among the digitally skilled, the view of a computer person as clever but antisocial still prevails, which can be unattractive to youths, particularly girls, with few aspiring to be a computer person.

However, there appears to be a lack of studies that use a theoretical basis to investigate these factors. Cohoon and Aspray [15] suggest that the use of a theory could help to evaluate and transform information that is gathered in to knowledge and then to predict the results of any associated action.

\subsection{Social Cognitive Career Theory (SCCT)}

Social Cognitive Career Theory (SCCT) [37] is derived from Social Cognitive Theory (SCT) which focused on the interaction between person, environment and behaviour [5]. The SCCT framework focusses on personal, cognitive and contextual factors for career/academic choices. It has three models: the interest model, choice model and performance model. Lent et al. [37] argued that "... our model may help explain the academic paths that people select". A review of empirical research based on SCCT by Sheu and Bordon [53] found that "The majority of studies tested hypotheses of the interest/choice and satisfaction models among adolescents and college students in Asian and European countries". Beyer [7] also suggested that "Social psychological variables are excellent candidates for factors to be studied because they have been shown to influence career choices".

There are a number of other models of motivation such as the Expectancy Value Model (EVM) [20] that could have been used as the basis of this research. SCCT was chosen because prior work has shown that its constructs can help identify the factors that influence career/academic choice [53]. Based on the previous studies, this study has adopted four factors from SCCT to help identify and understand reasons why students choose to study CS at university: These are: prior experience, social support, self-efficacy and outcome expectation. These factors are explained, and their choice justified, in the following sections.

\subsection{Prior Experience}

Prior experience refers to exposure to the subject prior to making the choice to study at university. In this case, it includes computer exposure and usage, computing subjects studied at school and programming-related activities. Taylor and Mounfield [56] found that there was a significant relationship between female success in $\mathrm{CS}$ at college and prior experience in computing. Beyer [7] also found that prior experience is a significant factor influencing female participation in computing courses. Similarly, He and Freeman [28]) conclude "Results suggest that females feel less confident with computers because they have learned less and practiced less" (this could also be categorized as 'self-efficacy' see later). Cohoon and Aspray [15] argue that computer experience either formal, such as computer courses at school, or informal, such as computer games, provide students with initial impressions and information about computing. Schulte and Knobelsdorf [51] observed that the nature of prior computing experience can shape attitudes and foster commitment from some while deterring others from pursuing CS. Denner et al. [18] suggest that three widely held beliefs - support from others, motivation, and prior experience play a vital role in the intention of females to pursue CS. Brown et al. [10] found that concentrating on students in early ages at schools helped to promote interest in CS.

\subsection{Social Support}

Social support refers to the surrounding environment, such as family, peers and teachers. A recent Google report emphasised the need for parents, students and educators to be made more aware of the benefits of CS education [26]. Numerous studies have identified the significance of social support as an influence on females to choose to study CS $[19,57,61,63]$. Mishkin et al. [43] found that female students making an engineering career choice are influenced by social support more than male students. Some studies indicate 
the importance of role models for female students $[4,8,60]$. According to Alvarado and Judson [3] introducing female students to female role models in CS could encourage them to pursue a computing degree. On the other hand, Heinze and $\mathrm{Hu}$ [30] argue that support from family and friends is not a powerful influence on the choice of students to pursue careers in IT. Social support and role models were not considered top factors for CS students in studies in Kuwait [21], Armenia [24] or Serbia [42].

\subsection{Self-efficacy}

According to Social Cognitive Theory (SCT), people perform tasks based on their capabilities and beliefs [5]. The main component of SCT is self-efficacy, defined by Bandura [5] as “... people's judgments of their capabilities to produce designated levels of performance". Self-efficacy has been examined in numerous studies [7, 14, 29, 30, 63]. Self-efficacy for female students in computing is influenced by both prior experience and knowledge of computers [28]. In Taiwan, Fan and Li [23] found that female CS students felt more confident in their ability than male students because of prior computing experience. Heinze and $\mathrm{Hu}[30]$ and Beyer [7] suggest that self-efficacy, interest and knowledge of computers all make females less likely than males to study CS. Similarly, a Google report [25] suggests that females are less confident in their skills and therefore less likely to study CS. Often the confidence and self-efficacy of females towards STEM subjects are less than of males, even though females perform just as well as males [2]. Lehman, Sax, and Zimmerman [36] found that female students rated themselves lower than male students in terms of CS ability. Most people are attracted to, and pursue, tasks and fields in which they are confident.

\subsection{Outcome Expectation}

Outcome expectation refers to the desired result of an action or behaviour. Lent et al. [38] suggest that there are a number of theories which suggest that outcome expectation can play a key role in motivating behaviour. Advisers should be aware of negative expectations, because some of these expectations are often misguided, or illogical, and may influence students' choices [54]. In Kuwait, El-Bahey and Zeid [21] found that the most important factor influencing a decision to study CS to be career and future considerations. A Google investigation [25] into factors that influence young women to pursue degrees in CS found that the "...perception of Computer Science as a career with diverse applications and a broad potential for positive societal impact" was a top factor. Similarly, a later Google report [26], found that “... most students and parents in the U.S. have a positive image of computer science work". Thus, the perceptions of parents regarding CS may also encourage females to study CS degrees (see also section 2.4 Social Support).

\section{STUDY DESIGN}

\subsection{Research Aim and Question}

The aim of this study is to investigate the factors that motivate students to choose to study CS at university. The study is the first phase of a larger study that will also include a wide-scale questionnaire-based survey constructed from the findings reported here. The aim is addressed by the following research question: What influence do students' prior experience, social support, selfefficacy and outcome expectation have in the choice to study a computer science degree at university?

\subsection{Design of the Interview}

The instrument used in this study was a semi-structured interview. In a semi-structured interview, questions are pre-planned, but the researcher can change the question order or ask additional questions to explore related topics, depending on how the conversation evolves [48].

The interview was constructed using Social Cognitive Career Theory as a foundation [37]. Interview questions were constructed for each of the four SCCT components using a range of prior research that had also used this theory as a foundation $[13,16,34$, $46,52,59,66]$. As a result, 32 questions were identified, 10 exploring prior experience, 5 on social support, 6 on outcome expectation, 3 on self-efficacy, and 8 questions on related topics. The study was given university ethics approval in September $2017^{1}$.

The prior experience questions explored: favourite subject at school; when subjects first used a computer and for what purpose; aspects of CS studied at school; what aspects were enjoyable or not; class environment for males and females; any programming experience; view on the importance of studying CS at school; how school experience influences the choice to study CS at university.

The social support questions explored: sources of encouragement to study CS; influential figures that may have inspired the choice to study CS; the role of parents, teachers counsellors and school in the choice; differences between male and female in terms of support.

The outcome expectation questions explored: expectations prior to studying CS; expectations now; career expectations; expectations after graduation; the influence of expectations on the choice to study CS; whether CS-related careers are attractive to females.

The self-efficacy questions explored: perceived ability to study $\mathrm{CS}$; programming and problem solving skills; thoughts on the importance of programming and problem solving skills.

Other questions explored: CS student characteristics; society perceptions; what can be done to attract more females into CS; when it was decided to study CS; why chose to study CS; biggest influence in choice.

Subjects were asked their name, nationality, gender and to describe the type of school that they attended prior to university. Subjects were also told that interviews would be recorded and that all data would be anonymised - their names would never be recorded with their data. Throughout this paper subjects are referred to by their subject number and gender e.g. P16(F) represents subject number 16 who is female.

\subsection{Pilot Study}

At the start of the research, the interview questions and process were tested in a small pilot study with two subjects. This was to ensure that the interview process ran smoothly, to check that none of the questions appeared to cause difficulty and to get an idea of the time taken to complete an interview. No major issues were

\footnotetext{
1 The final set of survey questions is openly available at: http://dx.doi.org/10.15129/7c80a42a-9b70-4d60-a28f-42f75b45e783
} 
encountered in this pilot. The estimated interview time of 30 minutes came from this stage. As there were no major issues, the data from these subjects are included in the final results.

\subsection{Subjects}

Seventeen subjects participated in the interviews, 11 female (F), 5 male $(\mathrm{M})$ and 1 gender-neutral $(\mathrm{Mx})$. The students were all at varying stages of a Computer Science (or CS-related) undergraduate degree at one of three Scottish universities Strathclyde (3M, 6F, 1Mx), Stirling (1M, 2F) and Edinburgh (1M, $3 \mathrm{~F})$. In order to obtain insights from CS students at different stages of their degree, subjects from all years of undergraduate study were interviewed.

The subjects had a range of backgrounds prior to university, both in terms of type of education and the country of education. Although all the interviews took place at Scottish universities, seven of the subjects were educated at schools outside of Scotland (2 England, 2 Spain, 1 Italy, 1 Latvia, 1 India). Furthermore, the type of schools varied - the majority of subjects were educated at state schools but five were educated at fee-paying schools. One subject attended a female-only school.

Subjects were obtained by sending an email to student mailing lists, it requested participation and told them the purpose of the interview. The email stated that the researchers were particularly keen to interview female subjects. Subjects were told that the interview would last approximately 30 minutes, that it had ethics approval and that their names would not be associated with their interview responses. Subject were all given a $£ 5$ shopping voucher as compensation for their time.

\section{DATA ANALYSIS}

A content analysis approach was using in this study to analyse the data. Content analysis is "... the intellectual process of categorizing qualitative textual data into clusters of similar entities, or conceptual categories, to identify consistent patterns and relationships between variables or themes" [32]. According to Elo and Kyngäs [22] content analysis has three stages: preparing the data, organizing the data into categories and subcategories, and reporting the findings.

The data preparation stage consisted of transcribing the recorded interviews. The transcription of one interview generated about 10 pages of data. Categorisation of data was done using NVivo [1]. Transcripts were read carefully within NVivo and content categorized according to its relevance to SCCT constructs. As well as the categories included in SCCT, two further were identified - 'Perceptions' and 'Suggestions' - which were used for potentially interesting content that did not appear to belong in the SCCT categories. 'Perceptions' related to subjects' perceptions of students who study CS and also their perceptions of society's view of such students. 'Suggestions' captured suggestions made by subjects for schools and universities to improve the uptake of CS degrees, particularly by females. The content in these two additional categories was gathered partly in response to the 'other' questions, beyond SCCT, mentioned in section 3.2.

\section{RESULTS}

In this section, the main results are reported under the four SCCT categories: prior experience, social support, self-efficacy, outcome expectation; together with additional categories: perceptions and suggestions. This section reports the data - mostly using counts and example quotations. It is acknowledged that stating the numbers of respondents in qualitative studies such as this is potentially controversial [41]. In the following, the number of subjects making a point is often stated, the intention being to make statements such as 'some' or 'most' more precise [6]. There is no attempt to interpret the significance of the stated numbers.

\subsection{Prior Experience}

The prior experience category includes formal and informal learning, computing class environment and any internships fulfilled before university. Twelve of the subjects stated that they had studied a computing subject at school. However, there was considerable differences in the computing curricula studied. Two subjects only studied computing at school when they moved from abroad to Scotland in their last year of school.

Three subjects stated that they gained programming experience while at school, P5(F) said: "I had a good teacher who did a lot of extra projects with us, and we got to do a lot of programming, we learned Python as a part of the course in school". Another subject, P13(F), reported a similarly positive school experience: "I had a really good experience when I took Computer Science in my high school. ... And all of that encouraged me to take up Computer Science in my university".

Others reported that their computing experience was limited to information technology and the use of applications. P7(F) said: "We just did Microsoft programs, no coding or anything like that, it would just be IT". Similarly, P15(F): "It was mainly just learning what the internet is and internet safety. We didn't really do much actual computing until I came to university".

Three subjects experienced no computing at school. P13(F) said: "I didn't actually take it at school, I thought it was a bit useless to be honest". P17(M) said that they chose to study CS at university despite not studying any at school: "I don't think it would had made much difference for me personally, because I was already interested and knew a fair bit".

Seven of the subjects gained their computing experience outside of school, often using online courses or teaching themselves. P6(M) said: "Outside I used Code Academy to learn Python". In addition, two of the subjects did a computing internship while at school, and then they decided to study CS. P1(F) said: "I went to a company and did a four week internship where I did some computer science stuff in a real working environment. That's when I decided to choose it".

A few subjects commented on the compulsory nature of their school class and its impact on the gender mix. P16(F) said: "It was fine. It was a mandatory class, so it wasn't really male-dominated ...”. On the other hand, P6(M) stated: “... in Advanced Higher there was only eight of us, all boys".

\subsection{Social Support}

The social support theme includes encouragement from others, which might influence the student's choice to pursue CS, such as family, peers, teachers and mentors.

Nine of the subjects talked about how their family encouraged them to choose CS. For example, P12(F) said: "My parents were always supportive when I was talking about it. They didn't have to suggest it because I was the first person to come up with it, but they were very happy and excited about the choice." P5(F) said: "When I mentioned it to my parents, they obviously thought yeah, that's 
really good, you're talented at that". $\mathrm{P} 8(\mathrm{~F})$ said: "My dad didn't want me to do Maths and he suggested Computer Science". Some subjects mentioned their cousins or uncles, for example, P13(F) said: "My cousin who kind of influenced me in my early years".

Eight of the subjects stated that they had been influenced by school teachers to pursue CS. For example, P12(F) said: "I think, in my case, the fact that the teacher had made it sound very interesting and important, it made it a really clear choice for me to go and study Computer Science." Some of the subjects said that their computing teachers were their favourite teacher at school. For instance, P1(F): "I actually really enjoyed the teacher I was with. He was just a really fun teacher to have". P8(F) mentioned that her Maths teachers suggested the CS degree to her: "I did ask my Maths teachers in high school that I wanted to do something related to Maths, but not Maths, and not any engineering, and they suggested Computer Science".

Other sources of social support were friends and internship mentors. P14(M) said that: "One of my dad's friends, I went to talk to before the university, because he actually works in ... Computer Engineering." $\mathrm{P} 17(\mathrm{M})$ mentioned his friends: "I have quite a few friends who study and work in computer-related subjects. They told me about what they were learning, so I want to do that". P1(F) identified the encouragement of a mentor: "... only through the internship. I was given a mentor who ... really encouraged me to do Computing".

\subsection{Outcome Expectation}

The expectation category includes career options, desire to gain knowledge of CS, and to help society. These three expectations were gathered mainly using responses to the questions: What do you expect from studying computer science? What do you expect to do after graduation?

Sixteen of the subjects identified the career options associated with a CS degree. P10(F) said that a CS degree: “... will help you get a job quick", while P14(M) mentioned job-variety and salary: "... there are quite a lot of good, well-paid jobs that are available". Some of the subjects mentioned the potential to set up your own business, P5(F) said: “... you can be self-employed, do your own apps, and make your own things".

Seven of the subjects identified the general value of CS knowledge across a range of subject areas and skills. P11(F) said: "I think it just gives you very useful skills that really put you ahead in life".

Six subjects identified helping society as an outcome expectation. P13(F) said: " ...maybe doing [CS] benefits society, and maybe discovering something or making something really good which would be beneficial for everyone".

Eleven of the subjects indicated that they chose to study CS rather than their favourite subject at school due to the perceived career opportunities. This was explored explicitly with the questions on favourite subject at school, and, if it wasn't CS, why they chose to study CS instead. For example, P3(M) said: "I didn't see a clear career path with history". Also, P5(F) said: "There's plenty of jobs available in it. I'm quite lucky that I enjoy Computing rather than Art, because Art is a lot harder to get a job in at the end".

Interestingly, nine of the subjects indicated that they planned to continue to postgraduate study after completing their first degree in a CS-related subject.

\subsection{Self-Efficacy}

The self-efficacy category includes subjects' opinion of their abilities, skills, verbal persuasion and emotions [5].

Twelve of the subjects said that they had a good background in computing and mathematics, and indicated a confidence in their ability and skills to study CS. P13(F) said: "Before university, I could do programming in $C++$. I could do a bit of SQL, and Mathematics was one of my main subjects in high school, I could do a lot of problem solving as well, so I am quite confident actually in my ability". P12(F) stated that: "I had very little of a Computing background, but I really enjoyed Maths, I did a few Maths competitions, which are purely based on problem solving. I feel more confident about the Computing part". P14(M) said: "I had a Maths background, which was quite useful coming into this, I'm gaining confidence in myself as I go along".

Five female subjects expressed a lack of confidence. Some were in terms of their perceived mathematical ability. P1(F) said: "The only downside for me is just the maths". P16(F) said: "My confidence in my maths ability kind of hinders me". Another two expressed more general concerns. P2(F) said: "I'm not confident, I'm struggling. It's not easy, I wouldn't say I have skills, I'm on my way to gaining skills". Another who came from abroad P8(F) said: "I didn't have it at school. And most people who live here had it at school and it was a normal subject. So I'm not very confident in my ability."

Another of the self-efficacy aspects is verbal persuasion. This is the support and motivations provided by individuals or institutions. P6(M) stated that they had a self-encouragement: "I think when I started doing programming for real, it was essentially oh wait, I'm actually okay at this. I would quite like to do stuff like this for my career". P17(M) said: "You see the results that you're getting and that either encourages you or discourages you. And because I've got good results, it's encouraging me". Other subjects identified support from others, such as the university. Another P9(Mx) mentioned parents: "My parents always told me I was good at it". P5(F) mentioned other people: "I didn't really realise it was a strength how much I was enjoying it until other people actually said you're really good at this...".

Also related to self-efficacy is the positive or negative emotions expressed by a subject based on their feelings and experiences from studying CS. Subjects expressed a wide range of emotions including: 'good', 'great', 'challenge', 'happy', and 'stressed'.

P2(F) mentioned: "My experience in high school, it made me scared of Computer Science". P8(F) said: "It makes me feel different, because I'm a woman doing Computer Science, ... But it also makes me feel interesting, in a way, since again I'm a woman but I enjoy the subject". When discussing her feelings, P1(F) said: "I was feeling a bit stressed. And I was angry because I was like "am I not good enough to do this course"? It's kind of I feel stressed, and then someone explains and then I feel better". P11(F) identified a range of emotions: “... sometimes empowered, sometimes it's a struggle for me. I think it's a hard degree. When you compare it to other degrees. But at the same time, I'm quite happy because it gives me so many possibilities. So in that sense I feel very lucky".

Three of the subjects associated challenge with the study of a CS degree, often in a positive sense. For example, P13(F) said: “... sometimes I'm tired. But I'm never frustrated, I'm never sad that I'm doing it because it makes me feel happy. So I feel challenged, I take the challenge positively". Another P5(F) said: "Challenged, a lot of 
the time ... And that does make me motivated to do more and do better". Three of the subjects related their enjoyment in creating and building new things to their study of CS. P4(M) said "My passion was driven by the love of creation". P5(F) said: "I really enjoyed doing the programming, and building my own things".

A number of subjects suggested that it was important to have certain passions and skills such as problem solving when choosing to study CS. P10(F) said: "I think if you're good at problem solving then you would like CS or Maths, because they're strongly connected. If you like programming you should consider CS". P5(F) said "I think some people are put off by the sound of problem solving, because they think of Maths and kind of difficult things". However, other subjects argued that some skills are not essential before studying CS. P5(F) reported " $A$ lot of people are put off by a lack of programming knowledge, and I think if they understood that you just need to start with an ability to learn and understand things, then you can really do quite well in a way".

\subsection{Perceptions}

The perceptions category is not part of the SCCT model. This category was introduced as a result of subjects' responses to questions such as: How are CS students perceived by society in general? What do other people think are the characteristics of CS students? Do you think a CS major is a male dominated major? This category is potentially important since perceptions about students who study CS may influence the choice to study the subject.

There were a range of positive and negative words used by the subjects about the characteristics of CS students, such as 'smart', 'shy' and 'nerd'. Nine of the subjects suggested characteristics associated with being non-social. P13(F) described CS students as "People who don't really go out and talk much, and just stay inside their houses or their labs and stare at their computer screens and aren't really sociable”. P2(F) stated: “... socially not very adept". Six of the subjects used the words "nerd" or "shy", while the word "geek" was used by three of the subjects.

Three of the subjects mentioned that CS students are mostly male. P1(F) said that "I think most people would automatically think it has to be a man. Even though there are girls". Other characteristics included "... playing lots of video games" $\mathrm{P} 11(\mathrm{~F})$, “... eating unhealthy things" $\mathrm{P} 17(\mathrm{M})$, and “... if you have long hair and you are male, you are probably into computing" $\mathrm{P} 4(\mathrm{M})$.

On the contrary, a few subjects associated quite positive characteristics with CS students. For example, P2(F) said: "I just see them as very smart and sort of like wealthy people", and $\mathrm{P} 16(\mathrm{~F})$ described them as: "... very analytical", and "... over-achievers".

The perceptions of family and society were also identified. P11(F) talked about families who have a negative attitude toward $\mathrm{CS}$ "In my case, my parents maybe wanted me to be more maths, and be a teacher, or study maybe Biology ... Computer Science was never something that was mentioned". P12(F) said: "Lots of parents see Computer Science as a very boring job ... I have lots of my friends (girls) whose parents would never let them do Computing Science because they think it's a very guy job".

Some of the subjects mentioned other STEM fields of study. P15(F) said: "I guess Computer Science is sometimes lumped in with Physics, which is mostly male-dominated", P17(M) stated: "I think that's the way all over the world. It's called STEM subjects. Historically and now male-dominated even though it has been slowly attracting more women".
Some subjects suggested that females were more likely to be encouraged to study business subjects. P10(F) said: "Most girls I think do business". P1(F) stated: "In my school, I don't know why, but a lot of girls were encouraged to do admin, which is much easier than Computing".

A number of female subjects thought that many females do not choose to pursue CS because it is a male-dominated subject. P2(F) said: "Maybe it's not very attractive for women who do not want to be among guys". P11(F) also mentioned: "One thing that would discourage me from studying CS would be thinking that I would be surrounded mostly by males ... as a young girl, that would be very discouraging".

Some of the subjects mentioned societal bias or stereotypes associated with females studying CS. For example, P17(M) stated: "There are stereotypes regarding Computing, that it's a man's subject and women should not do it, even though Ada Lovelace was the first programmer ever ... So personally I don't have any biases or preferences, as long as you're good at the subject". Also, P2(F) said: "More guys study it. I think because guys are more encouraged to do it. ... And girls are like go and design some clothes or go and learn how to do make-up. Or psychology that's for you". P5(F) pointed out: "I'm happy to say that in my class it's roughly half split, and we're all as equally knowledgeable as each other, and there's no real bias in that regard. But I think in wider society as a whole, especially in kind of the old guard of Computer Science there's still a bit of a stereotype and a bias".

Finally, P7(F) mentioned the role of the media saying: "I think just media and marketing, just having a very even spread and just not discriminating over gender whatsoever. Which is a bit tricky, because obviously in a male dominated field, there are just going to be more men to take photos of".

\subsection{Suggestions}

A final category that emerged from the data was suggestions by subjects about how to attract more female students to study CS at university. These include suggestions for both schools and for universities themselves.

The suggestions for schools included thoughts on how to prepare students to study CS and how to make them think about CS as a potential degree to study. Five subjects suggested that the computing subject taught at school needs to become more practical. P10(F) said: "I think they need to make it more practical, have more coding, rather than a textbook which tells you the file size, or a picture".

Six subjects said that computing at school should be seen as more important, even making it compulsory. P15(F) mentioned: "I would probably say, encourage people to take it at Standard Grade at least. Because for us, it wasn't compulsory ... I didn't realise the importance of computers".

Five subjects said that there should be more visits, talks and events about CS. P2(F) stated: "Send girls who are doing Computer Science. Inspiring girls. I'm going to say the same about female Computer Science teachers, because that worked very well for me".

$\mathrm{P} 4(\mathrm{M})$ suggested more exposure at an early age might help address gender imbalance: "I think that making computing more accessible to students of a young age, could be one way, since it would prevent early age judgement from different sexes to other sexes".

The final sub-category consisted of suggestions for universities to attract more females to study CS. Nine subjects suggested more 
visits and talks from females working in CS to the schools, especially potential role models. P8(F) explained her experience as:

"Some people from the university came to my school to give talks about CS. They were telling people what their project was for the last year and showing them how they built it. And I thought it was quite interesting, and other people as well thought that it's something they would like to do". Also, P15(F), said: "I suppose there could be more female role models in CS ... because most people you see who you generally associate with being good at CS are male".

Finally, six subjects mentioned more promotion and advertising of CS as a degree. P16(F) stated: “... I don't really think Computer Science is really well pushed. I think they tend to push the more popular subjects ...". Also P6(M) suggested: "Perhaps having special female-specific events, like having a women-only open day ...".

\section{DISCUSSION AND IMPLICATIONS}

This section aims to draw out the main findings from the above results, together with their implications, and to relate them to prior work.

\subsection{Prior Experience}

The findings show that most of the subjects studied a computing subject at school but the role and influence of computing at school seems complicated. The computing curricula seems focused mainly on computer usage and applications, and does not appear to be a significant factor in the decision of subjects to pursue a CS degree. A few subjects did identify good experiences, focusing on programming and problem solving, aided by good teachers. Many subjects had influential experiences outside of school via online self-learning and two subjects were influenced by their internships.

These findings are similar to those of Varma [59] and BuzzettoMore et al. [11] who found only a small percentage of CS and engineering students believed that their high school computing courses prepared them for a CS degree. Some of these subjects mentioned that their informal learning influenced them to pursue the CS degree. Nugent et al. [44] also found that a youth summer robotics camp helped influence students to choose to study CS.

Two female subjects changed their choice of degree to CS after experiencing introductory programming classes in their original degree. Four of the subjects chose to pursue a CS degree despite not studying CS at school. Numerous subjects expressed an interest in mathematics and problem solving at school and saw a CS degree as a way to further this interest. In their study of students in India, Hewner and Mishra [31] also found an association between an interest in mathematics and choosing to study CS.

\subsection{Social Support}

The findings highlight the important role that social support played for the subjects - the support of family, teachers, friends and mentors. This was particularly true for female subjects. This finding is consistent with the work of Teague [57] who found that the primary factor for females choosing computing was the encouragement they received. It is also supported by previous studies that found the support of parents and family members to be important $[19,40,58]$. Some of the subjects in this study stated that their parents and teachers observed their enjoyment of computing and therefore encouraged their pursuit of a CS career.
The finding here that some female subjects were encouraged by their teachers differs from the findings of Varma [59] who found that teachers rarely encouraged female students to choose a CS degree - in contrast to male students who were encouraged. Similarly, Kahle and Schmidt [33] concluded that: "It appears that most women are not encouraged by others to pursue a computer science career". Beyer and Haller [8] highlighted the importance of female computing teachers to influence female students to pursue CS, but in this study, there did not appear to be a clear influence of teacher gender on student choice.

\subsection{Outcome Expectation}

Another finding was the importance of career path for almost all the subjects. However, career path was not just concerned with the prospective job, but the value of a CS education for general careers and also the potential to help society using CS-related knowledge and skills. The potential career path seemed to attract many subjects whose favourite subjects were different from computing at school.

The issues raised in this study only partially fit with Bandura's [5] three categories of outcome expectation: physical (e.g. money), social approval (e.g. social position) and self-satisfaction outcomes. Career options may be partially influenced by money but also job satisfaction. Helping society is closely related to societal approval, though altruistic individuals are not necessarily driven by approval. Gaining knowledge of CS might be motivated by future financial or societal rewards. Margolis and Fisher [40] found that many females chose a CS degree because of the potential to apply their skills and knowledge in related fields to the benefit of society.

The majority of subjects mentioned the availability and variety of CS-related jobs, as well as the pay. This finding is similar to those of Hewner and Mishra [31] and Yasuhara [65]. Some subjects said that they chose to study CS rather than their favourite subjects at school, such as art or history, due to the associated career paths. Some subjects mentioned that they were drawn to the practical side of CS, as opposed to a theoretical science. Teague [57] previously found that female students were attracted to CS by the practical side of computing.

\subsection{Self-efficacy}

Self-efficacy is concerned with individuals' judgement of their abilities and potential. Most of the subjects expressed confidence in their ability to study CS - some of this confidence may stem from their background and experience in maths and computing. However, some of the females subjects did express a lack of confidence in their maths and/or CS ability, in keeping with the prior findings from Google [25]. Related to this, many subjects said that skills in maths, computing and problem solving helped build confidence. Again, social support seemed to play an important role helping to build self-confidence.

Overall, the study found a variety of attitudes towards CS, but the positive attitudes outweigh the negative - this is likely to be a reflection of the fact that all the subjects had chosen to study CS.

\subsection{Perceptions}

Perceptions was added as a category because there were many interesting points made by subjects that fell outside the original SCCT categories. Perceptions captures subjects' own views of students who study CS and their views on how society in general views them. In keeping with prior work [39, 47, 49, 50, 64], most 
of the characteristics identified by subjects were rather negative describing the traditional stereotypical view of CS students as 'geeks' or 'nerds'. However, often a subject would then say that the characteristic did not apply to them self or their colleagues " ... but I don't really follow any of those stereotypes". Another female subject said: "I would just say they're normal people like me do Computer Science". Subjects identified CS students as 'smart' or 'over-achievers'. Some subjects blamed society for these stereotypical perceptions of CS students.

Therefore, an important finding is that subjects recognise that society may still have quite a negative view of the typical CS student, which could potentially be off-putting for females in particular. However, it is important that the subjects themselves do not seem to have that negative viewpoint, generally seeing themselves and their colleagues as 'normal'.

\subsection{Suggestions}

There were numerous suggestions to help promote CS as a subject at schools, particularly to females, such as: provide early exposure before children start to form a view that it is a male-dominated subject; make it compulsory so both genders take it; make computing at school more practical (programming and problem solving); encourage female visitors to school to promote CS; improve marketing to females; and, emphasise female role models.

Other findings that could encourage increased female participation included: the importance of social support for females; emphasising the potential career paths, especially the value to society; challenging the traditional stereotypes; and, helping to improve self-confidence of females.

\section{THREATS TO VALIDITY}

There are a number of threats to the validity of this study. Perhaps the most significant is the threat posed by the choice of subjects. Firstly, they all currently study CS so the study does not collect the views of non-CS students. In this study the intention was to gather insights into the reasons why students chose to study CS. Future work could extend the work to investigate why students who might choose to study CS decide not to. The small numbers in the study are a major limitation on the generalisability of the results, as is the fact that the students are all from three Scottish universities. The intention is to broaden the survey with a more widespread, followup questionnaire study. Also, the subjects in this study self-selected themselves and may therefore have particular biases and opinions that they were keen to express, quite possibly views that are not representative of typical CS students.

The use of SCCT as a theoretical model on which to base the research is also a threat. Other models such as EVM [20] could be equally valid theoretical bases for the research. SCCT helped identify a wide range of questions on topics that might not otherwise have been explored e.g. on social support and career paths. There were also a number of more general questions at the end of the interview that were intended to identify any additional influences. The fact that later interviews rarely introduced factors not already mentioned in earlier interviews provides some reassurance that the most important factors were discussed.

Finally, an important threat is the approach taken to analysis, which is open to research bias and interpretation. To address this concern the paper documents the data content analysis used and aims to record a traceable route from results, to findings, to conclusions. To try to ensure reliability of transcription the first author checked all transcripts against the original audio recordings. The second and third authors checked the transcripts and the resultant codes to try to ensure consistency in the categorisation process.

\section{CONCLUSIONS}

This research has used Social Cognitive Career Theory to identify the factors that influence a student to choose to study Computer Science at university. The main findings include that social support was important to subjects, including encouragement from family and teachers, particularly for females. The career paths offered by a CS degree was also a major factor, not just the potential jobs, but also the general value of a CS education and the potential to make useful contributions to society. The stereotypical view of CS students as 'geeks' is still prevalent but is seen as outdated by students themselves. School education appeared to have limited influence on students' decision to study CS, though exposure to problem solving, programming, online self-learning and internships appeared to be important positive influences.

These findings have the potential to help schools and universities make a CS degree more appealing to students, especially to female students. Students and their families should be encouraged to see benefits of an education in CS, especially the breadth of opportunities it offers. More can be done to promote a much more positive view of CS and the students who study it. Much can be done, still, to improve the experiences that students have of CS during their school years. Subjects made numerous suggestions to make CS more attractive to females including: making it compulsory, teaching it earlier, making it more 'practical' involving programming and problem solving, and increasing the visibility of female exemplars and role models.

SCCT was found to be a useful theoretical model on which to base this research study, particularly to help identify the interview topics and questions. As a result, subjects appeared to provide a comprehensive insight into the factors that influenced their choice to study CS. The interview seemed to cover the majority of the factors that subjects considered important - by the end of the interviews it was rare for subjects to identify factors that had not already been discussed. The use of SCCT has led to novel findings on the potential importance of social support and outcome expectancy (career paths) as well as interesting insights into the role of prior experience and self-efficacy.

This study is the first of two phases of research. Future work will use these results to construct an online survey to explore these findings quantitatively with a larger subject base. The same topics are to be investigated with students from a different country and culture. Finally, it would be interesting to broaden the study to include students still at pre-university school and to students who considered the choice of a CS degree at university but instead chose to study a different degree subject.

\section{ACKNOWLEDGMENTS}

Amnah Alshahrani acknowledges the funding that she has received from Princess Nourah bint Abdulrahman University. The authors would also like to thank Neil Heatley from Edinburgh University and Carron Shankland from the University of Stirling for helping to identify subjects for the study. The authors are also extremely grateful to the 17 subjects who agreed to participate in this study. 


\section{REFERENCES}

[1] NVivo, version 10. 2014, QSR International.

[2] Research Briefing looking at gender balance in STEM subjects at School. September 2015, Scotland Education: http://www.educationscotland.gov.uk/Images/GenderBalanceBriefing_tcm4869326.pdf.

[3] Alvarado, C. and E. Judson, Using targeted conferences to recruit women into computer science. Communications of the ACM, 2014. 57(3): p. 70-77.

[4] Amelink, C.T. and E.G. Creamer, Gender differences in elements of the undergraduate experience that influence satisfaction with the engineering major and the intent to pursue engineering as a career. Journal of Engineering Education, 2010. 99(1): p. 81-92.

[5] Bandura, A., Social foundations of thought and action: A social cognitive theory. 1986: Prentice-Hall, Inc.

[6] Becker, H.S., Field work evidence. Sociological work: Method and substance, 1970.

[7] Beyer, S., Why are women underrepresented in Computer Science? Gender differences in stereotypes, self-efficacy, values, and interests and predictors of future CS course-taking and grades. Computer Science Education, 2014. 24(23): p. 153-192.

[8] Beyer, S. and S. Haller, Gender Differences and Intragender Differences in Computer Science Students: are Female CS Majors More Similar to Male CS Majors or Female Nonmajors? Journal of Women and Minorities in Science and Engineering, 2006. 12(4).

[9] Bock, S., et al., Women and minorities in computer science majors: results on barriers from interviews and a survey. Issues in Information Systems, 2013. 14(1): p. 143-152.

[10] Brown, N.C.C., et al. Bringing computer science back into schools: lessons from the UK. in Proceeding of the 44th ACM technical symposium on Computer science education. 2013. ACM.

[11] Buzzetto-More, N.A., O. Ukoha, and N. Rustagi, Unlocking the barriers to women and minorities in computer science and information systems studies: Results from a multi-methodolical study conducted at two minority serving institutions. Journal of Information Technology Education: Research, 2010. 9: p. 115-131.

[12] Chachashvili-Bolotin, S., M. Milner-Bolotin, and S. Lissitsa, Examination of factors predicting secondary students' interest in tertiary STEM education. International Journal of Science Education, 2016. 38(3): p. 366-390.

[13] Chao, S.-H., Exploring the gender inequity in tertiary computer science courses: influential factors in females' choices in Australia and Taiwan. 2013, Monash University. Faculty of Education.

[14] Cheryan, S., et al., Why are some STEM fields more gender balanced than others? Psychological Bulletin, 2017. 143(1): p. 1.

[15] Cohoon, J. and W. Aspray, A critical review of the research on women's participation in postsecondary computing education. 2006: Mit Press.

[16] De Lara, E. and L.Y. Liu, Identification, and the Crucial Role of Key Factors that Affect Women's Interest in Computer Science-A Qualitative Study of Women From Sweden, Mexico and India, in Department of Computer Science and Engineering. 2016, University of Gothenburg

[17] Denner, J., et al., Community College Men and Women: A Test of Three Widely Held Beliefs About Who Pursues Computer Science. Community College Review,SAGE 2014. 42(4): p. 342-362.

[18] Denner, J., L. Werner, and L. O'Connor, Women in Community College: Factors Related to Intentions to Pursue Computer Science. NASPA Journal About Women in Higher Education, 2015. 8(2): p. 156-171.

[19] DuBow, W., J. Weidler-Lewis, and A. Kaminsky. Multiple factors converge to influence women's persistence in computing: A qualitative analysis of persisters and nonpersisters. in Research on Equity and Sustained Participation in Engineering, Computing, and Technology (RESPECT), 2016. 2016. IEEE.

[20] Eccles, J., et al., \& Midgley, C.(1983). Expectancies, values and academic behaviors. Achievement and achievement motivation: p. 75-146.

[21] El-Bahey, R. and A. Zeid. Women in computing A case study about Kuwait. in 2013 IEEE Frontiers in Education Conference (FIE). 2013. IEEE.

[22] Elo, S. and H. Kyngäs, The qualitative content analysis process. Journal of advanced nursing, 2008. 62(1): p. 107-115.

[23] Fan, T.-S. and Y.-C. Li, Gender issues and computers: college computer science education in Taiwan. Computers \& Education, 2005. 44(3): p. 285-300.

[24] Gharibyan, H. and S. Gunsaulus, Gender gap in computer science does not exist in one former soviet republic: results of a study. ACM SIGCSE Bulletin, 2006. 38(3): p. 222-226.

[25] Google, Women Who Choose Computer Science _ What Really Matters The Critical Role of Encouragement and Exposure. 2014.

[26] Google. Images of Computer Science: Perceptions Among Students, Parents and Educators in the U.S. 2015; Available from: https://services.google.com/fh/files/misc/images-of-computer-sciencereport.pdf.
[27] Graham, H., et al., Women in ICT and Digital Technologies: An investigation of the barriers to women entering, staying, and progressing in the sector, and actions to ameliorate this - Executive Summary. 2016: Edinburgh: Skills Development Scotland.

[28] He, J. and L.A. Freeman, Are men more technology-oriented than women? The role of gender on the development of general computer self-efficacy of college students. Journal of Information Systems Education, 2010. 21(2): p. 203.

[29] He, J. and L.A. Freeman, Understanding the formation of general computer selfefficacy. Communications of the Association for Information Systems, 2010. 26(1): p. 12.

[30] Heinze, N. and Q. Hu, Why college undergraduates choose IT: a multi-theoretical perspective. European Journal of Information Systems, 2009. 18(5): p. 462-475.

[31] Hewner, M. and S. Mishra. When Everyone Knows CS is the Best Major: Decisions about CS in an Indian context. in Proceedings of the 2016 ACM Conference on International Computing Education Research. 2016. ACM.

[32] Julien, H., Content analysis. The SAGE encyclopedia of qualitative research methods, 2008. 2: p. 120-122.

[33] Kahle, J. and G. Schmidt, Reasons women pursue a computer science career: perspectives of women from a mid-sized institution. Journal of Computing Sciences in Colleges, 2004. 19(4): p. 78-89.

[34] Lang, C., Factors that shape student decision-making related to Information Technology study and career choices: a gendered analysis, in Centre for the Study of Higher Education. 2007, University of Melbourne.

[35] Laosethakul, K. and T. Leingpibul, Why females do not choose computing? A lesson learned from China. Multicultural Education \& Technology Journal, 2010. 4(3): p. 173-187.

[36] Lehman, K.J., L.J. Sax, and H.B. Zimmerman, Women planning to major in computer science: Who are they and what makes them unique? Computer Science Education, 2017. 26(4): p. 277-298.

[37] Lent, R.W., S.D. Brown, and G. Hackett, Toward a unifying social cognitive theory of career and academic interest, choice, and performance. Journal of vocational behavior, 1994. 45(1): p. 79-122.

[38] Lent, R.W., et al., Social cognitive career theory, in Career choice and development. 2002. p. 255-311.

[39] Lewis, C.M., R.E. Anderson, and K. Yasuhara. I Don't Code All Day: Fitting in Computer Science When the Stereotypes Don't Fit. in Proceedings of the 2016 ACM Conference on International Computing Education Research. 2016. ACM

[40] Margolis, J. and A. Fisher, Unlocking the clubhouse: Women in computing. 2003 : MIT press.

[41] Maxwell, J.A., Using numbers in qualitative research. Qualitative inquiry, 2010. 16(6): p. 475-482.

[42] Mirjana, I., et al., A Note on Performance and Satisfaction of Female Students Studying Computer Science. Innovation in Teaching and Learning in Information and Computer Sciences, 2010. 9(1): p. 32-41.

[43] Mishkin, H., et al., Career Choice of Undergraduate Engineering Students. Procedia-Social and Behavioral Sciences, 2016. 228: p. 222-228.

[44] Nugent, G., et al., A model of factors contributing to STEM learning and career orientation. International Journal of Science Education, 2015. 37(7): p. 10671088.

[45] Pappas, I.O., et al. Gender Differences in Computer Science Education: Lessons Learnt from an Empirical Study at NTNU. in NIK. 2016.

[46] Patterson Hazley, M., Successful female students in undergraduate Computer Science and Computer Engineering: Motivation, self-regulation, and qualitative characteristics. 2016, University of Nebraska-Lincoln, College of Education and Human Sciences.

[47] Powell, R.M. Improving the persistence of first-year undergraduate women in computer science. in ACM SIGCSE Bulletin. 2008. ACM.

[48] Robson, C., Real world research. 2nd. Edition. Blackwell Publishing. Malden, 2002.

[49] Rommes, E., et al., 'I'm not Interested in Computers': Gender-based occupational choices of adolescents. Information, Community and Society, 2007. 10(3): p. 299-319.

[50] Sáinz, M. and M. López-Sáez, Gender differences in computer attitudes and the choice of technology-related occupations in a sample of secondary students in Spain. Computers \& Education, 2010. 54(2): p. 578-587.

[51] Schulte, C. and M. Knobelsdorf. Attitudes towards computer science-computing experiences as a starting point and barrier to computer science. in Proceedings of the third international workshop on Computing education research. 2007. ACM.

[52] Shah, P., Cultural influences and new programs affecting women in Technology. 2011.

[53] Sheu, H.-B. and J.J. Bordon, SCCT research in the international context: Empirical evidence, future directions, and practical implications. Journal of Career Assessment, SAGE, 2017.

[54] Shoffner, M.F., et al., A qualitative exploration of the STEM career-related outcome expectations of young adolescents. Journal of Career Development, 2015. 42(2): p. 102-116. 
[55] Sinclair, J. and S. Kalvala, Exploring societal factors affecting the experience and engagement of first year female computer science undergraduates. 2015: p. 107116.

[56] Taylor, H.G. and L.C. Mounfield, Exploration of the relationship between prior computing experience and gender on success in college computer science. Journal of educational computing research, 1994. 11(4): p. 291-306.

[57] Teague, J., Women in computing: What brings them to it, what keeps them in it? ACM SIGCSE Bulletin, 2002. 34(2): p. 147-158.

[58] Tillberg, H.K. and J.M. Cohoon, Attaching women to the CS major. Frontiers: a journal of women studies, 2005. 26(1): p. 126-140.

[59] Varma, R., Exposure, Training, and Environment: Women's Participation in Computing Education in the United States and India. Journal of Women and Minorities in Science and Engineering, 2009. 15(3).

[60] Varma, R., Why so few women enroll in computing? Gender and ethnic differences in students' perception. Computer Science Education, 2010. 20(4): p. 301-316.

[61] Wang, J., et al., Gender Differences in Factors Influencing Pursuit of Computer Science and Related Fields. 2015: p. 117-122.

[62] Whitecraft, M.A. and W.M. Williams, Why aren't more women in computer science. Making software: What really works, and why we believe it, 2010: p. 221-238.

[63] Wilson, B.C., A Study of Factors Promoting Success in Computer Science Including Gender Differences. Computer Science Education, 2010. 12(1-2): p. 141-164.

[64] Wong, B., 'I'm good, but not that good': digitally-skilled young people's identity in computing. Computer Science Education, 2016. 26(4): p. 299-317.

[65] Yasuhara, K. Choosing computer science: Women at the start of the undergraduate pipeline. in Proceedings of the American Society for Engineering Education Annual Conference. 2005.

[66] Zeldin, A.L., S.L. Britner, and F. Pajares, A comparative study of the self-efficacy beliefs of successful men and women in mathematics, science, and technology careers. Journal of Research in Science Teaching, 2008. 45(9): p. 1036-1058. 